This document is confidential and is proprietary to the American Chemical Society and its authors. Do not copy or disclose without written permission. If you have received this item in error, notify the sender and delete all copies.

\title{
Sulfoxide synthase versus cysteine dioxygenase reactivity in a nonheme iron enzyme.
}

\begin{tabular}{|r|l|}
\hline Journal: & Journal of the American Chemical Society \\
\hline Manuscript ID & ja-2017-04251y.R1 \\
\hline Danuscript Type: & Article \\
\hline Complete List of Authors: & $\begin{array}{l}\text { Faponle, Abayomi; University of Manchester, Manchester Institute of } \\
\text { Biotechnology } \\
\text { Seebeck, Florian; University of Basel, Department for Chemistry } \\
\text { de Visser, Sam; University of Manchester, Manchester Institute of } \\
\text { Biotechnology }\end{array}$ \\
\hline
\end{tabular}

\section{SCHOLARONE ${ }^{m}$}

Manuscripts 


\section{Introduction.}

Nonheme iron dioxygenases are common and highly versatile enzymes in biology that participate in a range of vital functions for human health including DNA and RNA repair mechanisms, ${ }^{1}$ the biosynthesis of R-4hydroxyproline, ${ }^{2}$ and the metabolism of toxic cysteine in the body. ${ }^{3}$ As such, their function is critical for the biosystem and understanding the mechanism of action of these dioxygenases is important in the field of drug development therapies against a number of diseases. In particular, elevated levels of cysteine in the body have been correlated with a range of neurological diseases, including Alzheimer's and Parkinson's. ${ }^{4}$

In general, nonheme iron dioxygenases have a conserved structure with a central iron atom that is linked to the protein through nonheme interactions with either carboxylate (Asp/Glu) and/or histidine amino acid side chains. ${ }^{5}$ A common motif found in these dioxygenases is the facial orientation of the metal with two histidine and one carboxylate ligand, i.e. a 2-His/1-Asp(or 1-Glu) ligand environment. In octahedral symmetry, therefore, three ligand sites are occupied by the 2-His/1-Asp protein environment and the other three sites are available for binding of molecular oxygen and (co)-substrates. ${ }^{6}$ For instance, the $\alpha$-ketoglutarate dependent dioxygenases utilize $\alpha$-ketoglutarate $(\alpha K G)$ as a co-substrate on a nonheme iron center, which in a reaction with an iron(III)superoxo species is converted into succinate and $\mathrm{CO}_{2}$ and leaves a high-valent iron(IV)-oxo intermediate. The latter has been designated as the active oxidant in many nonheme iron dioxygenases and reacts with substrates efficiently through aliphatic hydrogen atom abstraction reactions or oxygen atom transfer. ${ }^{5,7}$ By contrast, several other nonheme iron dioxygenases do not use an extra cosubstrate. An example of this is $(S)$-p-hydroxymandelate synthase that utilizes p-hydroxyphenyl pyruvate as a substrate, which in a reaction with an iron(III)-superoxo leads to its decarboxylation and subsequent stereo- and regiospecific hydroxylation. ${ }^{8}$ 


\section{EgtB}

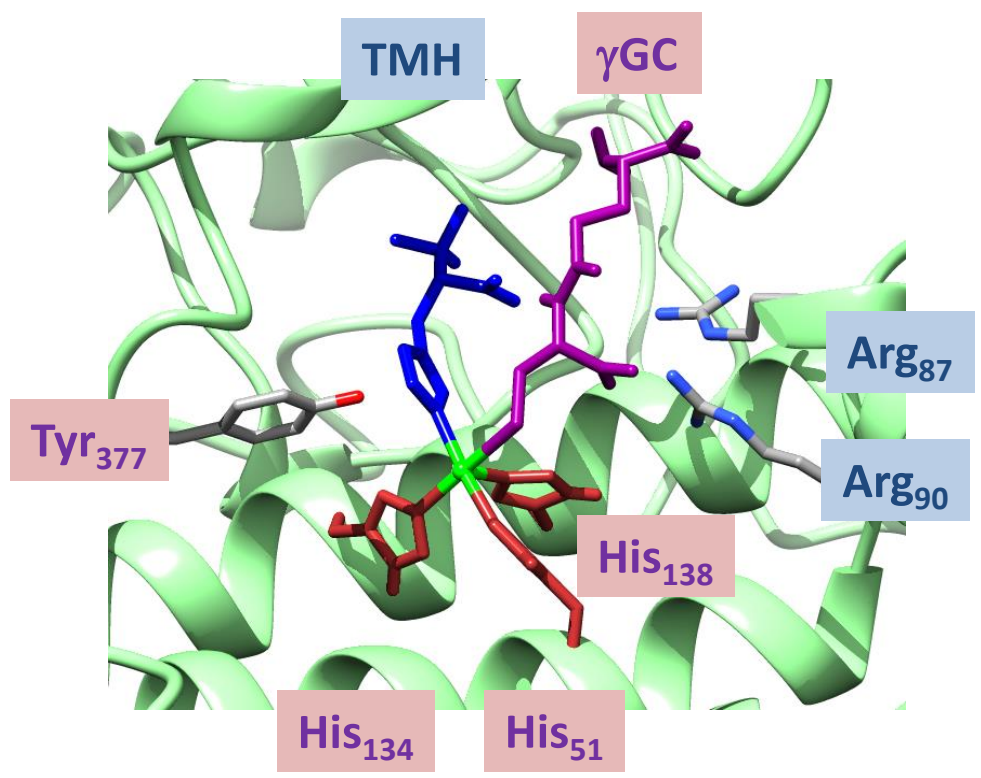

CDO

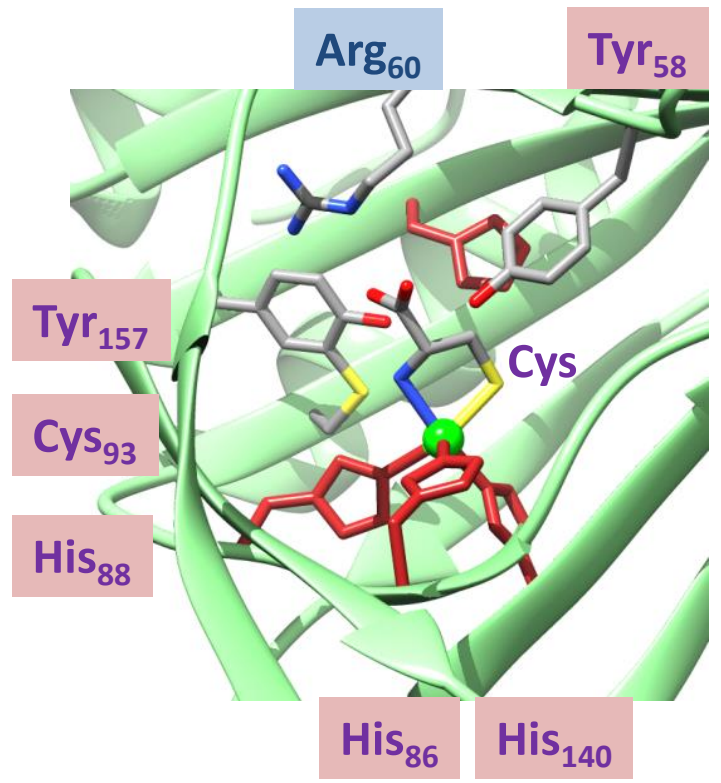

Figure 1. Active site structures of EgtB (left) and CDO (right) enzymes as taken from the 4 X8D and 4 IEV pdb files. The facial 3His ligand system is highlighted in wine-red and EgtB substrates (TMH and $\gamma \mathrm{GC}$ ) are shown in blue and purple.

Despite the fact that most nonheme iron dioxygenases contain a typical 2-His/1-Asp facial triad, actually a number of sulfur-activating nonheme iron dioxygenases utilize a 3-His ligand coordination environment instead. One of those is cysteine dioxygenase (CDO) that converts a cysteine amino acid into cysteine sulfinic acid as an initial step in the cysteine catabolism in the body. ${ }^{3,9}$ Another sulfur-activating nonheme iron enzyme is the ergothioneine biosynthesis protein $\mathrm{EgtB}$, which catalyzes the $\mathrm{C}-\mathrm{S}$ bond formation step between $\gamma$-glutamyl cysteine $(\gamma \mathrm{GC})$ and $\mathrm{N}$ - $\alpha$-trimethyl histidine (TMH) and the subsequent sulfoxidation of its product. ${ }^{10}$ Thus, enzymes that replace $\mathrm{C}-\mathrm{H}$ bonds with $\mathrm{C}-\mathrm{S}$ bonds are rare, and only few have been reported over the years. ${ }^{11}$ EgtB, to be specific, shows structural similarity to $\mathrm{CDO}$ with a central iron atom bound to the protein via a 3-His ligand orientation, although the enzymes are unrelated and also fold differently. In bacteria ergothioneine is generated to protect against oxidative stress, ${ }^{12}$ whereas in humans it may act as a reactive oxidative species. ${ }^{13}$ Understanding the mechanism for the biosynthesis of natural compounds relevant to aging processes in the body are important for pharmaceutical and medical development.

The active site structures of EgtB and CDO enzymes are shown in Figure 1 , as taken from the ${ }_{4} \mathrm{X} 8 \mathrm{D}$ and ${ }_{4} \mathrm{IEV}$ protein databank (pdb) files. ${ }^{14,15}$ Both of these are from substrate-bound crystal structure coordinates and show the iron bound in a facial 3-His coordination environment. Substrate cysteinate in CDO binds as a bidentate ligand through the amine and thiolate groups, while its carbox- ylate is involved in a salt bridge with an arginine residue $\left(\operatorname{Arg}_{60}\right)$ and is locked in hydrogen bonding interactions with a tyrosinate $\left(\mathrm{Tyr}_{58}\right.$ and $\left.\mathrm{Tyr}_{157}\right)$ and histidine $\left(\mathrm{His}_{155}\right)$ side chain. Note that the active site contains the unusual $\mathrm{Tyr}_{157}-\mathrm{Cys}_{93}$ crosslink with a covalent bond between the two amino acid residues. It is believed this crosslink has a steric effect on the overall reaction mechanism. ${ }^{16}$ The final ligand position of the metal is reserved for molecular oxygen. Density functional theory (DFT) modelling and quantum mechanics/molecular mechanics (QM/MM) studies showed the catalytic cycle to proceed with dioxygen binding to form an iron(III)-superoxo intermediate. ${ }^{17}$ The latter reacts with the thiolate group via oxygen atom transfer (OAT) to form a sulfoxide and an iron(IV)-oxo species. A final step relays the oxo to the sulfur atom of cysteine sulfoxide to form cysteine sulfinic acid products.

EgtB, by contrast to $\mathrm{CDO}$, binds two individual substrates, namely $\gamma \mathrm{GC}$ and TMH through their thiolate and imidazole substituents, respectively. These structures are held in position through hydrogen bonding interactions between each other as well as with amino acid side chains from, e.g. $\operatorname{Arg}_{87}$ and $\operatorname{Arg}_{90}$ (Figure 1). The final ligand site of the metal remains open for molecular oxygen to bind. Consequently, both $\mathrm{CDO}$ and EgtB form an initial iron(III)-superoxo intermediate in their catalytic cycles and both have a sulfide substrate ligand. Technically, therefore, a CDO-type mechanism could apply to EgtB leading to the dioxygenation of $\gamma \mathrm{GC}$ substrate. However, the latter is not known to form but instead the enzyme reacts as a sulfoxide synthase. 


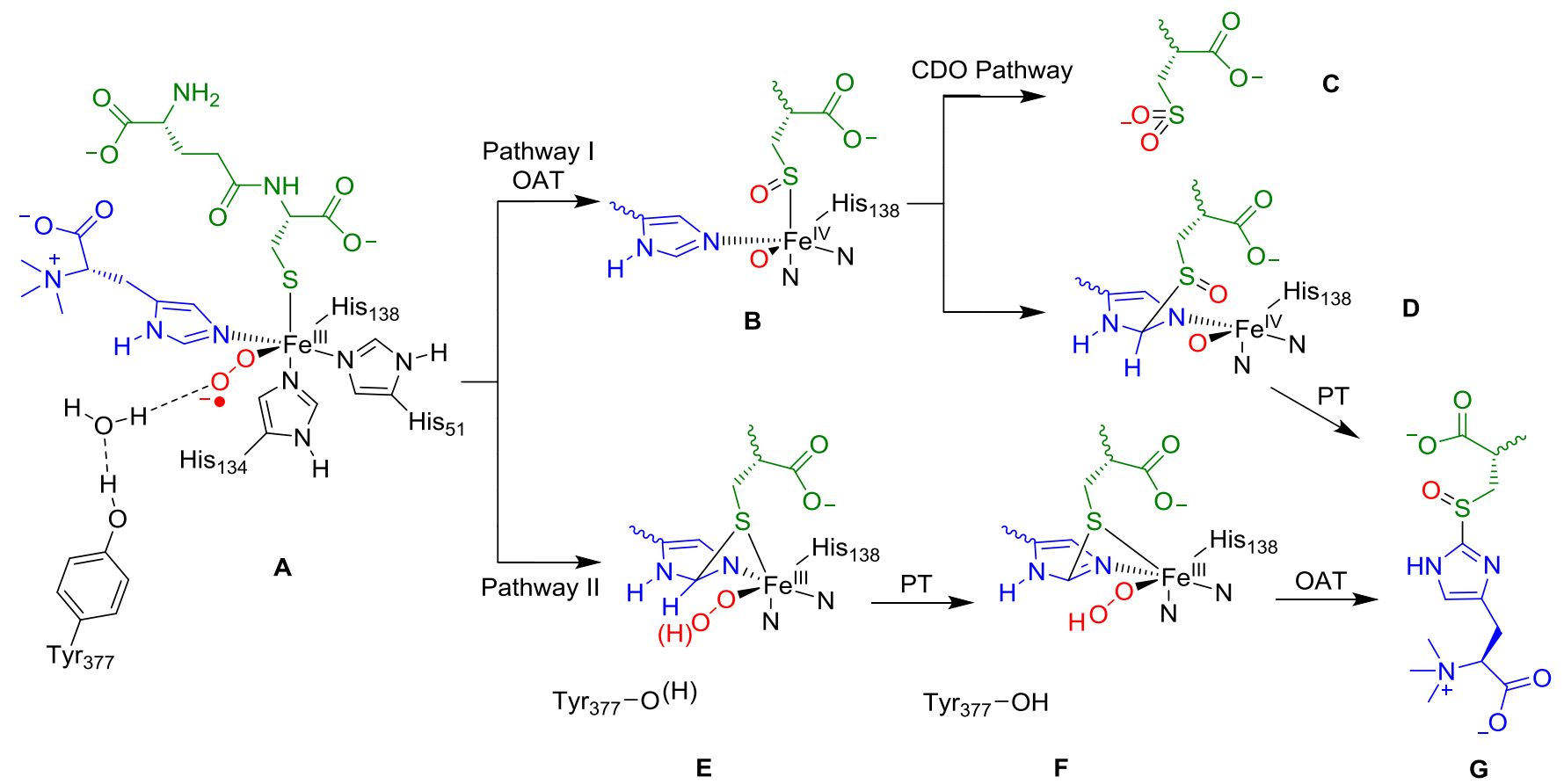

Scheme 1. Proposed reaction mechanisms of substrate(s) activation by EgtB via consecutive oxygen atom transfer (OAT) or proton transfer (PT) leading to dioxygenation or sulfoxide synthase activity.

Density functional theory modelling of active site models of EgtB in a polarized continuum model proposed a reaction mechanism starting with sulfoxidation (oxygen atom transfer, OAT) of $\gamma \mathrm{GC}$ followed by $\mathrm{C}-\mathrm{S}$ bond formation and deprotonation (PT) to form products: Pathway I in Scheme $1 .{ }^{18}$ However, this mechanism is in contradiction to recent kinetics and mutation studies that implicated an important function of the $\mathrm{Tyr}_{377}$ residue. ${ }^{14,19}$ Moreover, an initial sulfoxidation step could subsequently lead to a dioxygenation of the sulfur-containing substrate in analogy to CDO enzymes (CDO Pathway in Scheme 1 leading to product $\mathbf{C}$ ), which is not known to occur in Nature. The question, therefore, is why EgtB does not react through a dioxygenation of the thiolate group of the substrate and/or how it prevents this thiolate dioxygenation side-reaction. As the co-factor environment appears to play an important role in the reaction mechanism, we decided to gain an answer to this question by studying the reaction mechanism using the QM/MM methodology and by studying various alternative mechanisms.

The second pathway displayed in Scheme 1 highlights an alternative mechanism investigated here with a critical role for $\mathrm{Tyr}_{377}$. Again the EgtB catalytic cycle starts with binding of both substrates ( $\gamma \mathrm{GC}$ and $\mathrm{N}$ - $\alpha$-trimethyl histidine, TMH) on the iron center followed by molecular oxygen to create an iron(III)-superoxo structure (A in Scheme 1). We then considered various protonation states of the conserved tyrosine residue $\left(\mathrm{Tyr}_{377}\right)$ in the active site that could lead to protonation and/or hydrogen atom transfer to the superoxo group to form an iron(III/II)hydroperoxo species either in conjunction with or followed by a $C-S$ bond formation step between the two substrates (structure $\mathbf{E}$ ). Thereafter a proton transfer (PT) from the TMH imidazole group to either iron(III)superoxo or to $\mathrm{Tyr}_{377}$ gives structure F. Finally, an oxygen atom transfer from the metal to the linked substrates leads to the sulfoxide synthase products $(\mathbf{G})$. Site directed mutations that replaced $\mathrm{Tyr}_{377}$ by phenylalanine gave evidence of key functional components in the reaction mechanism as the $\mathrm{C}-\mathrm{S}$ bond between the substrates was not formed in the mutants, but instead a dioxygenation of the thiolate group of $\gamma \mathrm{GC}$ took place in a CDO-like mechanism. $^{19}$

In this work a novel catalytic reaction cycle for EgtB is presented as based on detailed QM/MM studies that take the full protein into consideration. Furthermore, many alternative side-reactions, including the one leading to dioxygenation of $\gamma \mathrm{GC}$ have been studied. The work gives explanations as to how the dioxygenation side reaction is prevented and highlights the functions of several active site residues. In particular, the work shows that the fast CDO-type side reaction is prevented through a proton coupled electron transfer from $\mathrm{Tyr}_{377}$ to iron(III)-superoxo group, which enables the slower $\mathrm{C}-\mathrm{S}$ bond formation to take place and blocks the sulfur dioxygenation sidereaction.

\section{Methods.}

We investigated the catalytic mechanism for sulfoxide synthase between TMH and $\gamma$ GC followed by oxygen atom transfer to obtain the ergothioneine product. We use a mixture of density functional theory (DFT) calculations on model complexes and full quantum mechanics/molecular mechanics (QM/MM) studies on the full 
protein. We will focus in the main text on the QM/MM results only; however, all details of the complete set of results are given in the Supporting Information.

Set-up of the system. Our studies started from the crystal structure coordinates of the substrate bound iron(II) resting state complex. ${ }^{14}$ The methods and procedures follow previously tested and benchmarked protocols that have been published in detail elsewhere, ${ }^{20,21}$ but will be briefly summarized here. Initially, the substratesbound resting state was converted into an iron(III)superoxo structure by manually adding a superoxo group. Subsequently, protons were added to the structure using the typical amino acid features at $\mathrm{pH} 7$ with the pdbtopqr software package. ${ }^{22}$ In this case, all Glu and Asp residues and the side-chain carboxylate group of the substrate were taken in the deprotonated form, whereas all Lys and Arg residues were protonated. Histidine residues ( $\mathrm{His}_{8}$,

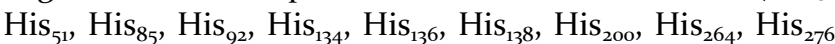
and $\mathrm{His}_{417}$ ) and the substrate imidazole moieties were taken in their singly protonated form. An iterative solvation procedure was applied to the constraint protein structure in a sphere with radius of $40 \AA$ (Figure S1, Supporting Information), which resulted in a final structure of 32,992 atoms including 8,739 $\mathrm{TIP}_{3} \mathrm{P}$ water molecules.

In the next stage of the model set up, the chemical system was heated and equilibrated to room temperature with the backbone atoms fixed using the Charmm forcefield. ${ }^{23}$ This was followed by a full molecular dynamics simulation for 1000 ps without geometric constraints in Charmm (see Figure S2 in the Supporting Information). Several snapshots from the MD simulation were selected as starting points for the QM/MM calculations, namely after 945, 950 and 955 ps; designated snapshots $\mathrm{Sn}_{945}$, $\mathrm{Sn}_{950}$ and $\mathrm{Sn}_{955}$. Key structures were optimized in all snapshots, while the full reaction mechanism was investigated for $\mathrm{Sn}_{950}$ only.

QM/MM calculations. The chemical system was separated into QM and MM regions, whereby the border region was described through hydrogen atom link-atoms and the interactions between the quantum mechanics and molecular mechanics were described by electrostatic embedding. ${ }^{24}$ The QM region contained the atoms highlighted in Scheme 2. Thus, the histidine ligands were abbreviated to methylimidazole, while the TMH substrate also included the carboxylate group. The $\gamma \mathrm{GC}$ substrate comprised the full cysteinate residue and was cut after the peptide bond. In addition to the direct ligands of the iron we included two crystal water molecules and the $\mathrm{Tyr}_{377}$ and $\operatorname{Arg}_{90}$ side chains.

The QM region was calculated with Turbomole ${ }^{25}$ at the DFT level of theory, whereas the Charmm forcefield ${ }^{23}$ was run through DL-POLY ${ }^{26,27}$ and the two software packages interfaced through ChemShell. ${ }^{28}$ All initial geometry optimizations and reaction scans utilized the unrestricted
B3LYP hybrid density functional method, ${ }^{29}$ in combination with an $\mathrm{SV}(\mathrm{P})$ basis set on all atoms: basis set $\mathrm{BS}_{1} .^{30}$ Single point calculations were performed on the optimized geometries with an all-electron Wachters-type basis set on iron and $6-311+G^{*}$ on the rest of the atoms: basis set $\mathrm{BS}_{2} .^{31}$

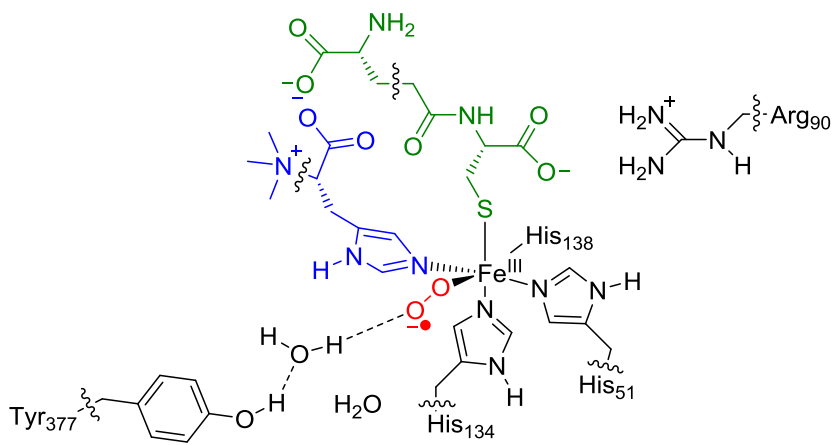

Scheme 2. Atoms included in the QM region. Wiggly lines identify bonds on the border of the QM and MM regions.

To test the effect of the density functional method on the spin-state energies, we did single point calculations at the QM/MM level of theory on several structures using the $\mathrm{BP} 86^{32}$ and $\mathrm{PBEo}^{33}$ protocols. However, no dramatic changes in spin state ordering and relative energies were obtained, so that we will focus on the B3LYP results only. A recent computational study on substrate sulfoxidation by nonheme iron(IV)-oxo complexes using more than 40 different computational methods and procedures showed that $B_{3} L Y P$ reproduces experimental enthalpies of activation within $4 \mathrm{kcal} \mathrm{mol}^{-1}$ and perfectly predicts regioselectivities and Hammett trends. ${ }^{34}$

\section{Results and Discussion.}

Before we discuss the reaction mechanisms of EgtB and how it compares to $\mathrm{CDO}$, we did an extensive set of calculations to validate the model, density functional method and basis sets. In particular, we compared the structure and spin-state ordering of key intermediates as compared to CDO enzymes and model structures. ${ }^{17,35}$

Model testing. Figure 2 displays QM/MM optimized geometries in the lowest lying singlet, triplet and quintet spin states of the iron(III)-superoxo structures (Re) for EgtB and CDO enzymes, whereby the data of the latter was taken from Ref $17 \mathrm{~b}$. Structurally, there are some key differences between the two systems that may affect their reactivities. In $\mathrm{CDO}$, the superoxo moiety is located in a very small binding pocket surrounded by mostly apolar residues including $\mathrm{Leu}_{95}$ and $\mathrm{Ile}_{133}$ (not shown in Figure 2) and the cross-linked pair $\mathrm{Tyr}_{157}-\mathrm{Cys}_{93}$. By contrast, the superoxo group in EgtB is found in a polar environment with a chain of water molecules connecting it to a tyrosine residue $\left(\mathrm{Tyr}_{377}\right.$ ), but also a $\operatorname{Trp}_{59}$ and $\mathrm{Gln}_{55}$ (Supporting Information, Figure $\mathrm{S}_{4}$ ). 


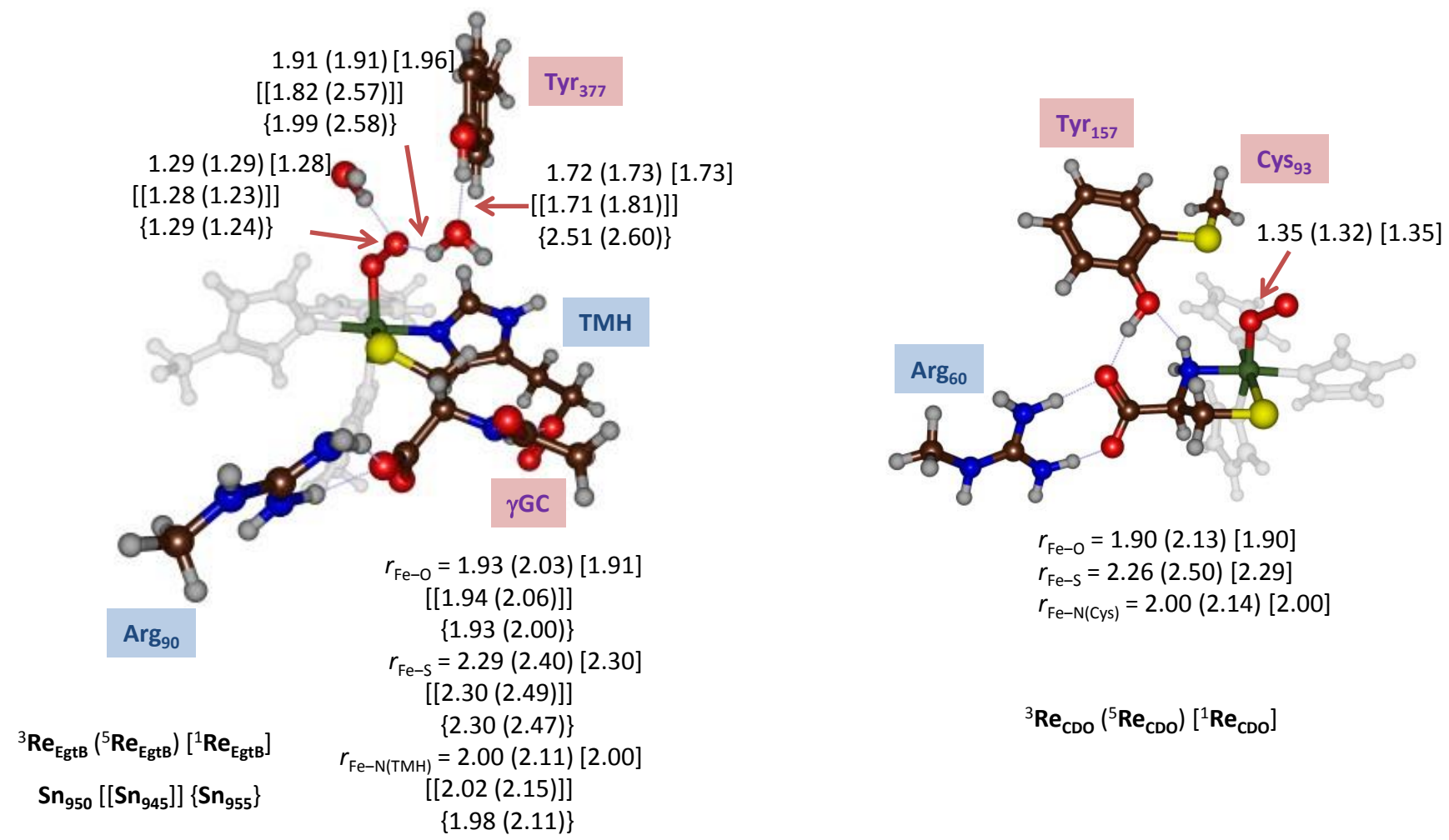

Figure 2. Optimized geometries of low-lying spin states of the iron(III)-superoxo reactant of EgtB (left) and CDO (right) as obtained with QM/MM. Data for CDO for snapshot $S_{250}$ from Ref ${ }_{17} \mathrm{~b}$. Bond lengths are in angstroms for snapshots $\mathrm{Sn}_{950}, \mathrm{Sn}_{945}$ and $\mathrm{Sn}_{955}$.

Two of these water molecules and the $\mathrm{Tyr}_{377}$ side chain were included in the QM region of the calculations. Another minor (and probably not relevant) geometric difference between EgtB and CDO is the position of the thiolate substrate bound to the metal with respect to superoxo. Interestingly, the carboxylic acid group of $\gamma \mathrm{GC}$ forms a salt bridge with $\mathrm{Arg}_{90}$, which is in almost the same position as the $\operatorname{Arg}_{60}$ residue in $\mathrm{CDO}$ that forms the salt bridge with the cysteinate carboxylic acid group. The iron(III)-superoxo complexes of EgtB were optimized in three different snapshots, namely $\mathrm{Sn}_{945}, \mathrm{Sn}_{950}$ and $\mathrm{Sn}_{955}$ and the singlet, triplet and quintet spin state structures are shown in Figure 2. In general, the optimized geometries, particularly the iron-ligand distances, show little variation between the various snapshots and a maximum deviation well below o.10 $\AA$ is seen. Therefore, the starting structure taken from the MD simulation has little effect on the metal-ligand distances. The only major differences seen between the three snapshot structures for both spin states relates to the position of the two water molecules we included in the QM region. As a result some hydrogen bonding interactions involving the water molecules have changed considerably. However, this does not seem to affect the spin-state splitting and relative energies dramatically.

Supporting Information Figure $\mathrm{S}_{3}$ gives an overlay of the crystal structure coordinates with that of $S_{n} n_{90}$ after full solvation and equilibration. In general, the MD snapshots have a similar fold as the crystal structure, although some groups have changed position slightly. One particular change relates to the aromatic ring of $\mathrm{Tyr}_{377}$ that is close to the iron center in the crystal structure, although in our iron(III)-superoxo optimized geometry it is slightly further away and the phenolate group of $\mathrm{Tyr}_{377}$ does not form a direct hydrogen bonding interaction with the superoxo moiety but there is a bridging water molecule in between.

The optimized geometries of the iron(III)-superoxo complexes of EgtB and $\mathrm{CDO}$ are very similar, particularly the metal-ligand distances. One noteworthy difference is the superoxo bond length, which is slightly longer in CDO at $1.32-1.35 \AA$ than in EgtB (1.29 $\AA$ ). Probably, this is due to the extensive hydrogen bonding network in EgtB that is lacking in CDO. As a result, the spin density distribution is more polarized to the distal oxygen atom in $\mathrm{CDO}$ as compared to EgtB.

The high-lying occupied and virtual orbitals are dominated by the $3 \mathrm{~d}$ orbital manifold on the metal and antibonding interactions along the superoxo bond. The metal 3d block splits into its usual $t_{2 g} / e_{g}$ sets of orbitals with three $\pi^{*}$-type orbitals $\left(\pi^{*}{ }_{\mathrm{xy}}, \pi^{*}{ }_{\mathrm{xz}}\right.$ and $\left.\pi_{\mathrm{yz}}^{*}\right)$ below the two of $\sigma^{*}$-type orbitals $\left(\sigma_{{ }^{2}{ }^{2} y^{2}}\right.$ and $\left.\sigma^{*}{ }^{2}\right)$. 


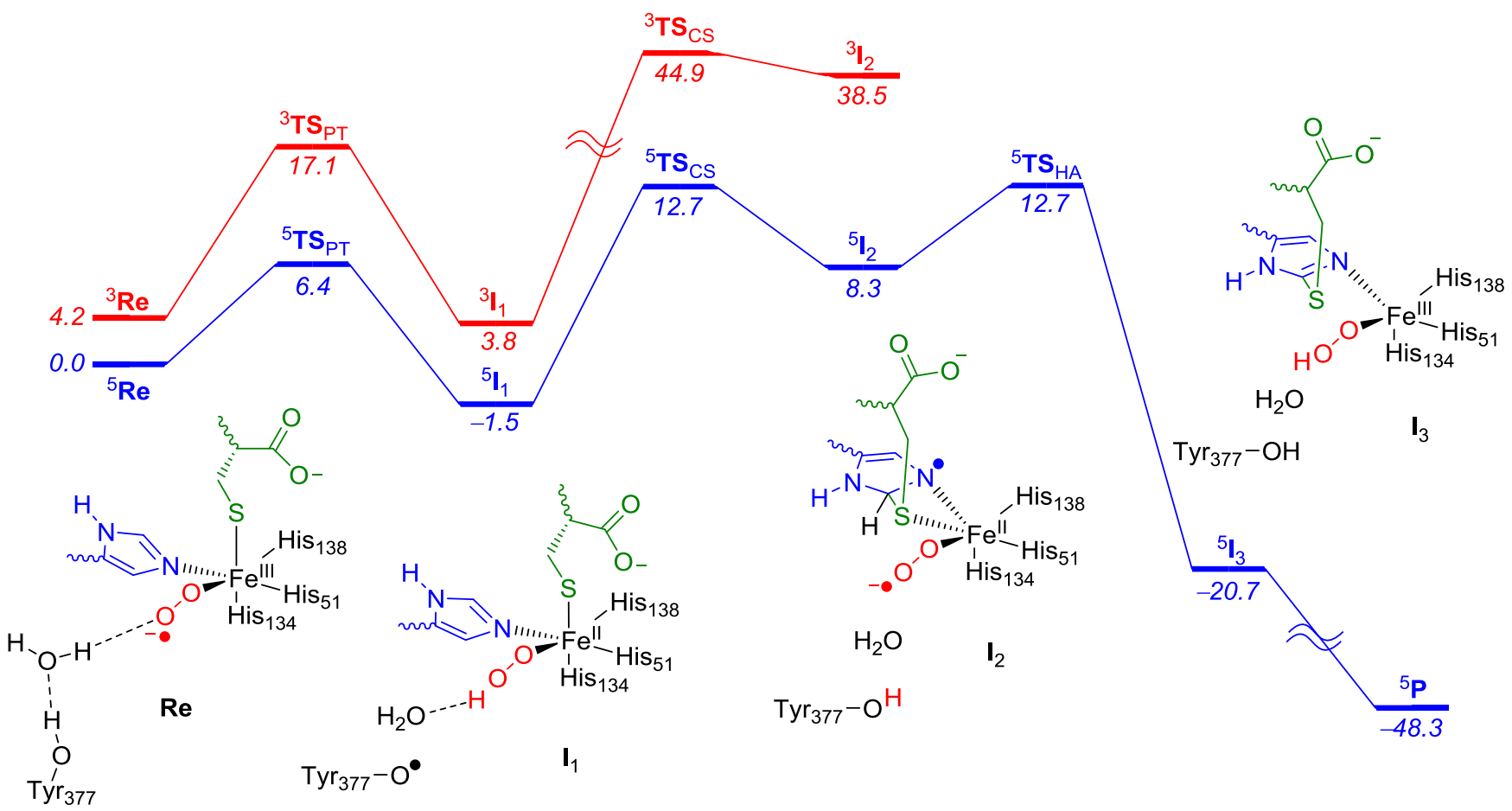

Figure 3. Potential energy landscape for sulfoxide synthase starting from the iron(III)-superoxo complexes in the triplet and quintet spin states. Relative energies represent $\triangle \mathrm{E}+\mathrm{ZPE}$ data in $\mathrm{kcal} \mathrm{mol}^{-1}$ as obtained at $\mathrm{B} 3 \mathrm{LYP} / \mathrm{BS} 2 / / \mathrm{B}_{3} \mathrm{LYP} / \mathrm{BS}$ :Charmm

Electronically, the ${ }^{1} \mathbf{R e}$ and ${ }^{3} \mathbf{R e}$ structures refer to a state with configuration $\pi_{\mathrm{xy}}^{*} \pi^{*}{ }_{\mathrm{xz}}{ }^{2} \pi_{\mathrm{yz}}^{*}{ }^{1} \pi^{*}{ }_{\mathrm{OO}}{ }^{1}$. By contrast, the quintet spin state is formed after the promotion of a $\pi^{*}{ }_{x z}$ electron into $\sigma^{*}{ }^{2}$. As expected from the orbital occupation, the singlet and triplet geometries are almost the same and at $\Delta \mathrm{E}_{\mathrm{BS} 1}+\mathrm{ZPE}$ level of theory we find both states close in energy. However, when the basis set is improved with polarization and diffuse functions, the singlet spin state is considerably destabilized. Despite the singlet spin state being the ground state in $\mathrm{CDO}$, herein for EgtB a quintet spin state ground state is found. Again, most likely this is due to the larger polarity of the iron(III)superoxo environment in EgtB as compared to CDO. One noteworthy difference found here between the ${ }^{5} \mathbf{R e}$ models for EgtB and CDO is spin density located on the cysteinate substrate group: $\rho_{\gamma \mathrm{GC}}=0.33$ in EgtB and $\rho_{\mathrm{Cys}}=0.05$ in CDO. The extra radical character on the substrate sulfur atom of the substrate in EgtB will make it more electrophilic and enable an attack on the histidine substrate group.

Relative energies show little variation between the three snapshots and, for instance, the triplet-quintet energy gap is calculated to be $\Delta \mathrm{E}_{\mathrm{BS} \mathrm{S}_{1}}+\mathrm{ZPE}=4.3[7.8]\{5.3\} \mathrm{kcal}$ $\mathrm{mol}^{-1}$ for snapshot $\mathrm{Sn}_{950}\left[\mathrm{Sn}_{945}\right]\left\{\mathrm{Sn}_{955}\right\}$, respectively, in favor of the high-spin state at B3LYP/BS1:Charmm. Single point calculations with a larger basis set on atoms in the QM region gives a triplet-quintet energy gap of $4.2 \mathrm{kcal}$ $\mathrm{mol}^{-1}$ instead. This value matches the recent study of Liao et $\mathrm{al}^{18 \mathrm{~b}}$ who obtained $1.6 \mathrm{kcal} \mathrm{mol}^{-1}$ using a large DFT model of close to 200 atoms. Most studies reported in the literature on nonheme iron(IV)-oxo and iron(III)superoxo intermediates report a high-spin ground state in analogy to what is found here. ${ }^{36}$ It appears, therefore, that $\mathrm{CDO}$ is the anomaly in this series, which most probably originates from its highly apolar active site pocket and the lack of hydrogen bonding interactions to the oxo and superoxo groups.

Sulfoxide synthase mechanism of EgtB. Subsequently, we calculated the mechanism of sulfoxide synthase starting from the iron(III)-superoxo complexes and the obtained energy landscape (at the $\triangle \mathrm{E}+\mathrm{ZPE}$ level of theory) is given in Figure 3. Although the reaction was proposed to start with a proton transfer from $\mathrm{Tyr}_{377}$ to iron(III)superoxo, ${ }^{14}$ instead the $\mathrm{QM} / \mathrm{MM}$ mechanism reveals a proton-coupled electron-transfer. Thus, the distal oxygen atom of the iron(III)-superoxo group is protonated through a Grotthuss mechanism from $\mathrm{Tyr}_{377}$ via a bridging water molecule via a transition state $\left(\mathbf{T S}_{\mathrm{PT}}\right)$. However, at the same time an electron is transferred back from the tyrosinate to form the iron(III)-hydroperoxo complex ( $\left.\mathbf{I}_{1}\right)$. Subsequently, a nucleophilic or radical attack of the sulfur atom on $\gamma \mathrm{GC}$ onto the $\mathrm{CE}_{1}$ atom of TMH via a transition state $\mathbf{T S}_{\mathrm{CS}}$ takes place that has the two substrates covalently linked through a sulfide bond. 


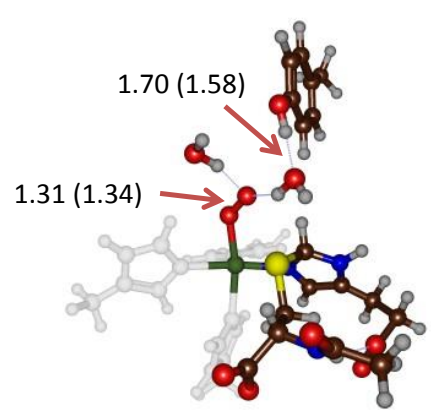

$$
\begin{aligned}
& r_{\mathrm{Fe}-\mathrm{O}}=2.09(1.86) \\
& r_{\mathrm{Fe}-\mathrm{S}}=3.14(3.13) \\
& r_{\mathrm{Fe}-\mathrm{N}(\mathrm{TMH})}=2.12(1.99) \\
& r_{\mathrm{S}-\mathrm{C}}=1.98(1.93) \\
&{ }^{5} \mathrm{TS}_{\mathrm{CS}}\left({ }^{3} \mathrm{TS}_{\mathrm{CS}}\right)
\end{aligned}
$$

$$
{ }^{5} \mathrm{TS}_{\mathrm{PT}}\left({ }^{3} \mathrm{TS}_{\mathrm{PT}}\right)
$$

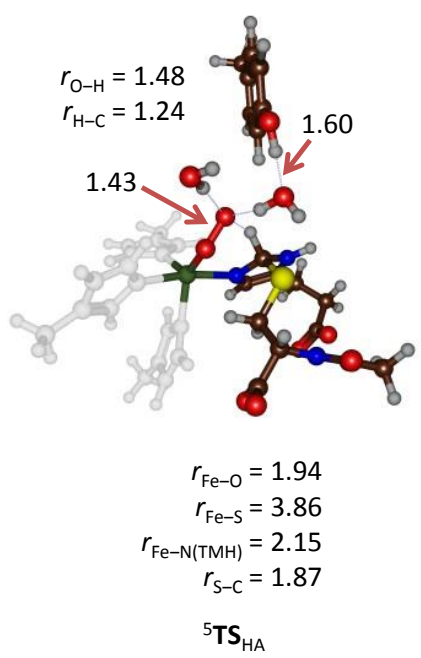

Figure 4. Optimized QM geometries of key intermediates in the catalytic cycle of EgtB as calculated with QM/MM as optimized at $\mathrm{B}_{3} \mathrm{LYP} / \mathrm{BS}$ :Charmm. Bond lengths are in angstroms and structures are taken for snapshot $\mathrm{Sn}_{950}$. The Arg ${ }_{90}$ residue is hidden to guide the eye.

Simultaneously to the $\mathrm{C}-\mathrm{S}$ bond formation, i.e. along the pathway around $\mathbf{T S}_{\mathrm{CS}}$ (vide infra), the iron(III)hydroperoxo group relays its hydrogen atom back to $\mathrm{Tyr}_{377}$ and an electron is transferred from sulfur to iron to form an iron(II)-superoxo species $\left(\mathbf{I}_{2}\right)$. In a the next reaction step, the iron(II)-superoxo $\left(\mathbf{I}_{2}\right)$ picks up a hydrogen atom from the sulfur-linked imidazole group via a transition state $\mathbf{T S}_{\mathrm{HA}}$ to form an iron(II)-hydroperoxo species and the sulfide bridged substrate, intermediate $\mathbf{I}_{3}$. In the final step of this mechanism the sulfoxidation takes place by the iron(II)-hydroperoxo intermediate to form the final R-sulfoxide product $\mathbf{P}$. Our calculated mechanism leads to the product with the experimentally determined stereochemistry, ${ }^{13 \mathrm{~b}}$ while a previous computational study led to the S-isomer instead. ${ }^{18 b}$

On all spin state surfaces starting from reactants, the hydrogen atom transfer from $\mathrm{Tyr}_{377}$ to the distal oxygen atom $\left(\mathrm{O}_{\mathrm{d}}\right)$ of the iron(III)-superoxo group requires a small barrier: $6.4(17.1) \mathrm{kcal} \mathrm{mol}^{-1}$ in the quintet (triplet) spin states with an almost thermoneutral driving force of -1.5 (3.8) $\mathrm{kcal} \mathrm{mol}^{-1}$. The second reaction step in Figure 3 is rate determining and leads to formation of the carbonsulfur bond via $\mathbf{T S}_{\mathrm{CS}}$, which splits the $\mathrm{C}=\mathrm{N}$ double bond of the imidazole group of TMH back into a single bond and leaves a radical on the nitrogen atom. Our QM/MM calculated mechanism up to ${ }^{5} \mathbf{I}_{2}$ matches results recently reported for a large DFT model complex very well, ${ }^{18 \mathrm{~b}}$ where a hydrogen atom abstraction barrier of $7.7 \mathrm{kcal} \mathrm{mol}^{-1}$ and a C-S bond formation step of $12.8 \mathrm{kcal} \mathrm{mol}^{-1}$ on the quintet spin state was found. However, their mechanism after ${ }^{5}$ TS $_{\mathrm{CS}}$ converges to an iron(III)-hydroperoxo with high energy that was ruled out. In our QM/MM calculations the hydrogen bonding network, by contrast, enables a fast and simultaneous proton transfer to $\mathrm{Tyr}_{377}$ and gives a much lower lying iron(II)-superoxo intermediate. As a consequence, the $\mathrm{C}-\mathrm{S}$ bond formation happens prior to the sulfoxidation in a low-energy alternative to the one proposed in Ref 18. Furthermore, the mechanism shown in Figure 3 supports experimental observation as will be discussed below.

Note that during the C-S bond formation the iron(III)hydroperoxo loses its proton back to $\mathrm{Tyr}_{377}$ simultaneously, as will be discussed in more detail later in this paper. In the triplet spin state this barrier is well over $40 \mathrm{kcal}$ $\mathrm{mol}^{-1}$ and hence no reactivity on the triplet spin state surface can be expected. On the quintet spin state an $\mathrm{S}-\mathrm{C}$ bond formation barrier of $12.7 \mathrm{kcal} \mathrm{mol}^{-1}$ is encountered. However, in the next step, the aromaticity is brought back into the imidazole ring through a hydrogen atom transfer to iron(II)-superoxo via another barrier of $4.4 \mathrm{kcal} \mathrm{mol}^{-1}$ above ${ }^{5} \mathbf{I}_{2}$ to form an iron(II)-hydroperoxo complex $\mathbf{I}_{3}$ with a large exothermicity of well over $30 \mathrm{kcal} \mathrm{mol}^{-1}$. Therefore, the step from ${ }^{5} \mathbf{I}_{2}$ to ${ }^{5} \mathbf{I}_{3}$ will be irreversible. The final stage of the mechanism encounters negligible barrier heights and leads to the sulfoxide and an iron(III)-hydroxo complex $(\mathbf{P})$ in a strongly exothermic process.

For the pathway from ${ }^{5} \mathbf{I}_{2}$ to products, we also investigated two alternatives, where the sulfoxidation happens prior to the hydrogen atom transfer, see Tables S16 and $\mathrm{S}_{7} 7$ in the Supporting Information. Thus, starting from structure ${ }^{5} \mathbf{I}_{2}$ we scanned the $\mathrm{S}-\mathrm{O}$ distance between each of the oxygen atoms (distal and proximal) of the superoxo moiety to the sulfur atom of $\gamma \mathrm{GC}$ in a stepwise manner, whereby the $\mathrm{S}-\mathrm{O}$ distance was fixed at specific intervals and the rest of the structure was energy minimized. These two scans gave barrier heights of 8.4 and $5.9 \mathrm{kcal} \mathrm{mol}^{-1}$ with respect to the energy of ${ }^{5} \mathbf{I}_{2}$, respectively, for transfer of the proximal or distal oxygen atom of iron(II)-superoxo to sulfur. The oxygen atom transfer values are higher in energy than the hydrogen atom abstraction barrier ${ }^{5} \mathbf{T S}_{\mathrm{HA}}$. Therefore, the QM/MM calculations predict an initial C-S bond formation, followed by hydrogen transfer and conclude the reaction with the sulfoxidation mechanism. 


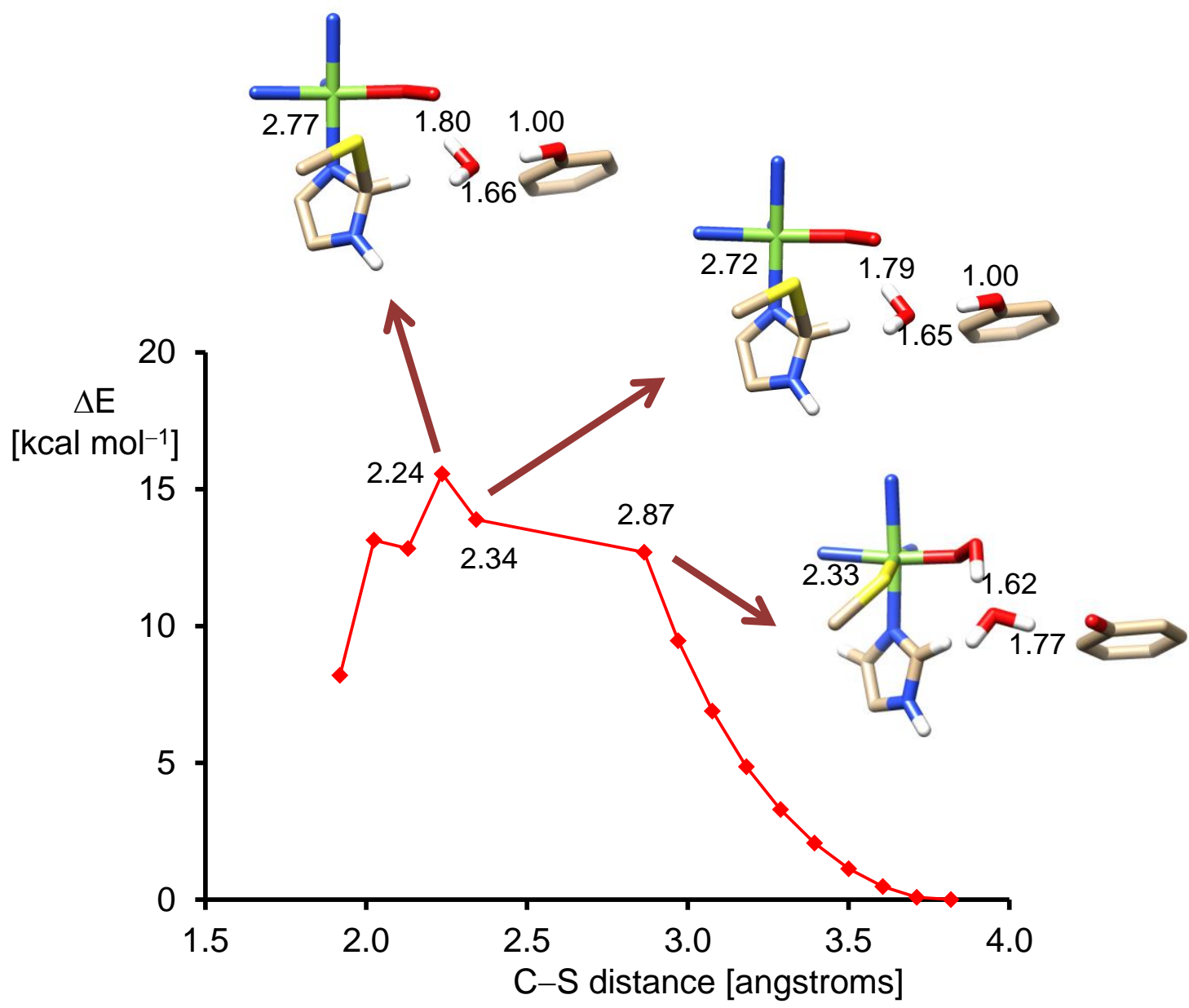

Figure 5. Geometry scan for the C-S bond formation step from ${ }^{5} \mathbf{I}_{1}$ (right-hand-side) to ${ }^{5} \mathbf{I}_{2}$ (left-hand-side). Energies taken relative to ${ }^{5} \mathbf{I}_{1}$ as obtained with QM/MM at B3LYP/BS1:Charmm using fixed C-S bond distance. Also shown are extracts of geometries with bond lengths in angstroms.

It should be mentioned here that the scans for the distal or proximal oxygen atom transfer from ${ }^{5} \mathbf{I}_{2}$ reached a maximum in energy, and consequently a reaction barrier for sulfoxidation from intermediate ${ }^{5} \mathbf{I}_{2}$. However, beyond these barriers the $\mathrm{C}-\mathrm{S}$ bond broke again and a local minimum was reached where a bridging $\mathrm{Fe}-\mathrm{O}-\mathrm{O}-\mathrm{S}$ intermediate was formed, similar to the initial oxygen activation step in CDO enzymes. ${ }^{17}$ As such, these oxygen atom transfer pathways from intermediate ${ }^{5} \mathbf{I}_{2}$ may not be viable.

Optimized QM/MM geometries of key intermediates along the reaction mechanism of Figure 3 are shown in Figure 4. In general, the optimized geometries are not dramatically different from those obtained for analogous nonheme iron dioxygenases calculated previously. ${ }^{37,38}$ In ${ }^{3.5} \mathrm{TS}_{\mathrm{PT}}$ the tyrosinate is already deprotonated and has lost its proton to a bridging water molecule. In the transition state this bridging water molecule, which formally is $\mathrm{H}_{3} \mathrm{O}^{+}$, transfers one of its protons to the distal oxygen atom of the iron(II)-superoxo group. In ${ }^{5} \mathbf{T S}_{\mathrm{PT}}\left({ }^{3} \mathbf{T S}_{\mathrm{PT}}\right)$ the transferring proton is located almost midway in between these groups, namely at a distance of $1.15(1.21) \AA$ to the distal oxygen atom and at $1.27(1.23) \AA$ from the oxygen atom of the water molecule, respectively.

At this stage the metal-ligand distances retain their values from the reactant complexes and only a small elongation in the $\mathrm{Fe}-\mathrm{O}$ distance is seen. In these transition states spin density is starting to accumulate on the $\mathrm{Tyr}_{377}$ group ( $\rho_{\mathrm{Tyr}}=0.46$ in ${ }^{3} \mathbf{T S}_{\mathrm{PT}}$ and $\rho_{\mathrm{Tyr}}=0.47$ in ${ }^{5} \mathbf{T S}_{\mathrm{PT}}$ ), which implicates that a proton-coupled-electron-transfer takes place, whereby simultaneously to the protonation of the superoxo group the metal abstracts an electron from tyrosinate.

In the first intermediate $\left(\mathbf{I}_{1}\right)$, the $\mathrm{Tyr}_{377}$ group contains a radical $\left(\rho_{\text {Tyr }}=1.00\right.$ in $\left.{ }^{3,5} \mathbf{I}_{1}\right)$ and is connected to a hydrogen bonding chain of water molecules to iron(III)hydroperoxo. The distal hydroxo group is in hydrogen bonding distance $\left(2.86 \AA\right.$ in $\left.{ }^{5} \mathbf{I}_{1}\right)$ to the thiolate group of $\gamma \mathrm{GC}$. In general, protonation of the superoxo group leads to elongation of the $\mathrm{O}-\mathrm{O}$ bond from about $1.29 \AA$ in ${ }^{3,5} \mathbf{R e}$ to $1.40 / 1.44 \AA$ in ${ }^{5} \mathbf{I}_{1} /{ }^{3} \mathbf{I}_{1}$. The electronic configuration of these intermediates identifies ${ }^{5,3} \mathbf{I}_{1}$ as iron(III)-hydroperoxo complexes with orbital occupation $\pi_{\mathrm{xy}}^{*}{ }^{2} \pi_{\mathrm{xz}}^{*} \pi_{\mathrm{yz}}{ }^{1} \pi_{\mathrm{Tyr}}{ }^{1}$ in 
the triplet spin state and $\pi_{\mathrm{xy}}^{*}{ }^{2} \pi^{*}{ }_{\mathrm{xz}}{ }^{1} \pi^{*}{ }_{\mathrm{yz}}{ }^{1} \sigma^{*}{ }_{\mathrm{z}} 2^{1} \pi_{\mathrm{Tyr}}{ }^{1}$ in the quintet spin state, whereby $\pi_{\mathrm{Tyr}}$ represents the singly occupied orbital on the $\mathrm{Tyr}_{377}$ group.. Attempts were made to swap molecular orbitals to obtain an intermediate ${ }^{3} \mathbf{I}_{1}$, with $\pi^{*}{ }_{\mathrm{xy}}{ }^{2} \pi^{*}{ }_{\mathrm{xz}}{ }^{\uparrow} \pi^{*}{ }_{\mathrm{yz}}{ }^{\uparrow} \sigma^{*}{ }_{\mathrm{z}}{ }^{\uparrow} \pi_{\mathrm{Tyr}}{ }^{\downarrow}$ configuration but the wave function converged back to the ${ }^{3} \mathbf{I}_{1}$ state reported above.

Several pathways were investigated for the next step in the catalytic cycle, but we will focus on the lowest energy mechanism first. In the next section the alternative mechanisms will be described. The thiolate group of $\gamma \mathrm{GC}$ attacks the $\mathrm{CE} 1$ atom of $\mathrm{TMH}$ through a nucleophilic/radical attack in ${ }^{3,5} \mathbf{T S}_{\mathrm{CS}}$. In the transition state the C-S distance is shortened to 1.98 (1.93) $\AA$ in the quintet (triplet) spin state, respectively. At this stage, the $\mathrm{Fe}-\mathrm{S}$ bond breaks and distances of well over $3 \AA$ are recorded and consequently, the metal is reduced from sixcoordination to five-coordination. In the transition state this results in the conversion of iron(II)-hydroperoxo into iron(II)-superoxo through a proton-coupled-electrontransfer to $\mathrm{Tyr}_{377}$ that changes from a tyrosinyl radical to a tyrosine residue. This step has a very high barrier in the triplet spin state and consequently, we did not investigate the rest of the mechanism on this spin state.

The $\mathrm{C}-\mathrm{S}$ bond formation results in the breaking of the aromaticity in the imidazole group of TMH and creates a radical on the substrate. The iron(II)-superoxo group attacks the radical by abstracting the proton from the $\mathrm{CE} 1$ position, so that the imidazole group reverts back to an aromatic ring and hence gains stabilization energy. In ${ }^{5} \mathrm{TS}_{\mathrm{HA}}$ the transferring proton is at a distance of $1.48 \AA$ from the distal oxygen atom and at 1.24 $\AA$ from the carbon atom of TMH.

Details of the $\mathrm{C}-\mathrm{S}$ bond formation pathway are given in the geometry scan displayed in Figure 5. Thus, upon approach of the thiolate of $\gamma \mathrm{GC}$ on the TMH substrate the iron(II)-hydroperoxo group remains protonated. However, when a short interaction between sulfur and carbon is reached, e.g. below $2.34 \AA$, the proton moves rapidly to the tyrosine group and to form iron(II)-superoxo. This happens almost simultaneously with the $\mathrm{C}-\mathrm{S}$ bond formation that links the two substrates. Group spin densities give radical character on the tyrosinate group until a $\mathrm{C}-\mathrm{S}$ distance of $2.87 \AA$ is reached. At shorter distances, however, a proton coupled electron transfer happens and the radical character on $\mathrm{Tyr}_{377}$ disappears and at the same time increases on the TMH and $\gamma \mathrm{GC}$ groups. Therefore, at short range the attacking nucleophile gains radical character. The electron- and proton-transfer to $\mathrm{Tyr}_{377}$ that occur en route from $\mathbf{I}_{1}$ to ${ }^{5} \mathbf{T S}_{\mathrm{CS}}$ indicate that $\mathbf{I}_{1}$ must be in equilibrium with a less stable intermediate that contains a thiyl radical, an iron(II)-superoxo species and $\mathrm{Tyr}_{377}$ in reduced and protonated form. Unfortunately, an orbital swap from ${ }^{5} \mathbf{I}_{1}$ to attempt to generate this thiyl radical configuration failed and converged back to ${ }^{5} \mathbf{I}_{1}$ instead. In contrast to $\mathbf{I}_{1}$ this species $\left(\mathbf{I}_{1 \mathrm{~b}}\right)$ could approach the transition state without requiring en route proton- and outer sphere electron transfer (Scheme 3).

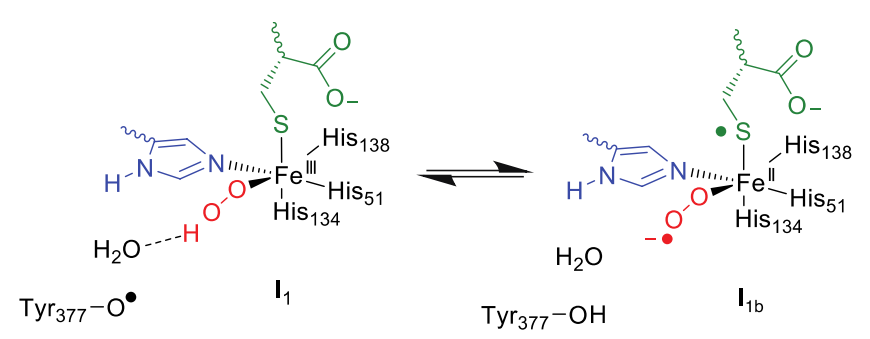

Scheme 3. Isoelectronic forms of $I_{1}$.

After the hydrogen atom abstraction the system relaxes to intermediate ${ }^{5} \mathbf{I}_{3}$, which is an iron(II)-hydroperoxo with the metal in five-coordination. Both distal $\left(\mathrm{O}_{\mathrm{d}}\right)$ and proximal $\left(\mathrm{O}_{\mathrm{p}}\right)$ oxygen atoms of the hydroperoxo group in ${ }^{5} \mathbf{I}_{3}$ are at almost equal distance to the sulfur atom: the $\mathrm{S}-\mathrm{O}_{\mathrm{d}}$ distance is $3.24 \AA$ and the $\mathrm{S}-\mathrm{O}_{\mathrm{p}}$ one is $3.18 \AA$. We find an almost barrierless pathway from ${ }^{5} \mathbf{I}_{3}$ to ${ }^{5} \mathbf{P}$ leading to an iron(II)-hydroxo and sulfoxide product complex $\left({ }^{5} \mathbf{P}\right)$ with a large exothermicity, whereby the attack on sulfur happens through the $\mathrm{OH}$ terminal group of the iron(II)hydroperoxo complex. We also attempted to transfer the proximal oxygen atom to sulfur instead but encountered a high energy pathway (Supporting Information) and, therefore, this is not a feasible mechanism.

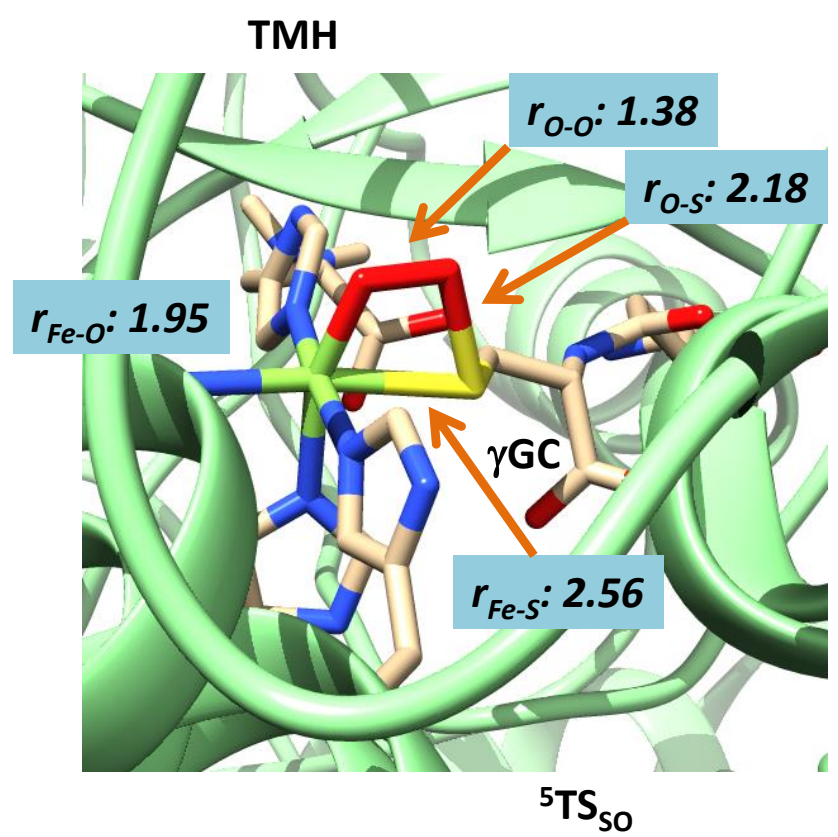

Figure 6. Optimized QM geometry of the S-O bond formation transition state for the reaction of iron(III)-superoxo with cysteine in EgtB. Data obtained with QM/MM at the $\mathrm{B}_{3} \mathrm{LYP} / \mathrm{BS}$ :Charmm level of theory with bond lengths in angstroms.

Cysteine dioxygenase pathway. In CDO enzymes an iron(III)-superoxo species is formed that reacts by con- 
secutive oxygen atom transfer to the sulfur atom of cysteine substrate to form cysteine sulfinic acid., ${ }^{3,17,39}$ We tested this mechanism for EgtB as well starting from ${ }^{5,3}$ Re by initially scanning the $\mathrm{S}-\mathrm{O}_{\mathrm{d}}$ distance through stepwise geometry optimizations with fixed S-O distance. Subsequently, the $\mathrm{S}-\mathrm{O}$ bond formation transition state $\left(\mathbf{T S}_{\mathrm{SO}}\right)$ was optimized and the quintet structure is given in Figure 6. We also located a triplet spin barrier but found it well higher in energy by at least $30 \mathrm{kcal} \mathrm{mol}^{-1}$, therefore, will not consider it further.

The ${ }^{5} \mathbf{T S}_{\mathrm{SO}}$ structure shown in Figure 6 shows strong similarities to the analogous structure reported for CDO enzymes and calculated with QM/MM, where Fe-O, O$\mathrm{O}, \mathrm{O}-\mathrm{S}$ and Fe-S distances of 1.93, 1.31, 2.23 and $2.84 \AA$ were obtained, respectively. ${ }^{1 \mathrm{~b}}$ The only difference comes from a much shorter Fe-S distance of $2.56 \AA$, which probably relates to the choice of the basis set, which previously was shown to strongly affect calculated Fe-S distances. $^{40}$
Energetically, in CDO the ${ }^{5} \mathbf{T S}_{\mathrm{SO}}$ barrier was located at $\Delta \mathrm{E}_{\mathrm{QM} / \mathrm{MM}}+\mathrm{ZPE}=14.4 \mathrm{kcal} \mathrm{mol}^{-1} .^{17 \mathrm{~b}}$ By contrast, a value of $13.1 \mathrm{kcal} \mathrm{mol}^{-1}$ for our EgtB model calculated here is found. As such, little changes in barrier height of sulfur activation by iron(III)-superoxo is found upon changing the substrate and the protein environment. Nevertheless, the CDO-type mechanism is higher in energy than the hydrogen abstraction from $\mathrm{Tyr}_{377}$ and hence, the latter will be the favorable pathway for EgtB. Consequently, the $\mathrm{Tyr}_{377}$ amino acid has an essential function in EgtB to prevent direct dioxygenation of the sulfur-containing substrate and guide the reaction mechanism to the preferred $\mathrm{C}-\mathrm{S}$ bond formation step. Indeed, studies on the $\mathrm{Y}_{377} \mathrm{~F}$ mutant of EgtB gave dominant sulfur dioxygenation through a CDO-type reaction mechanism. ${ }^{14}$ The experimental observation that the $\mathrm{Y}_{377} \mathrm{~F}$ mutant still has $0.1 \%$ of the wild type sulfoxide synthase activity may imply a second proton source in the catalytic cycle. An analysis of our optimized structures (Figure $\mathrm{S}_{4}$ ) proposes a possible role for $\mathrm{Tyr}_{380}$.

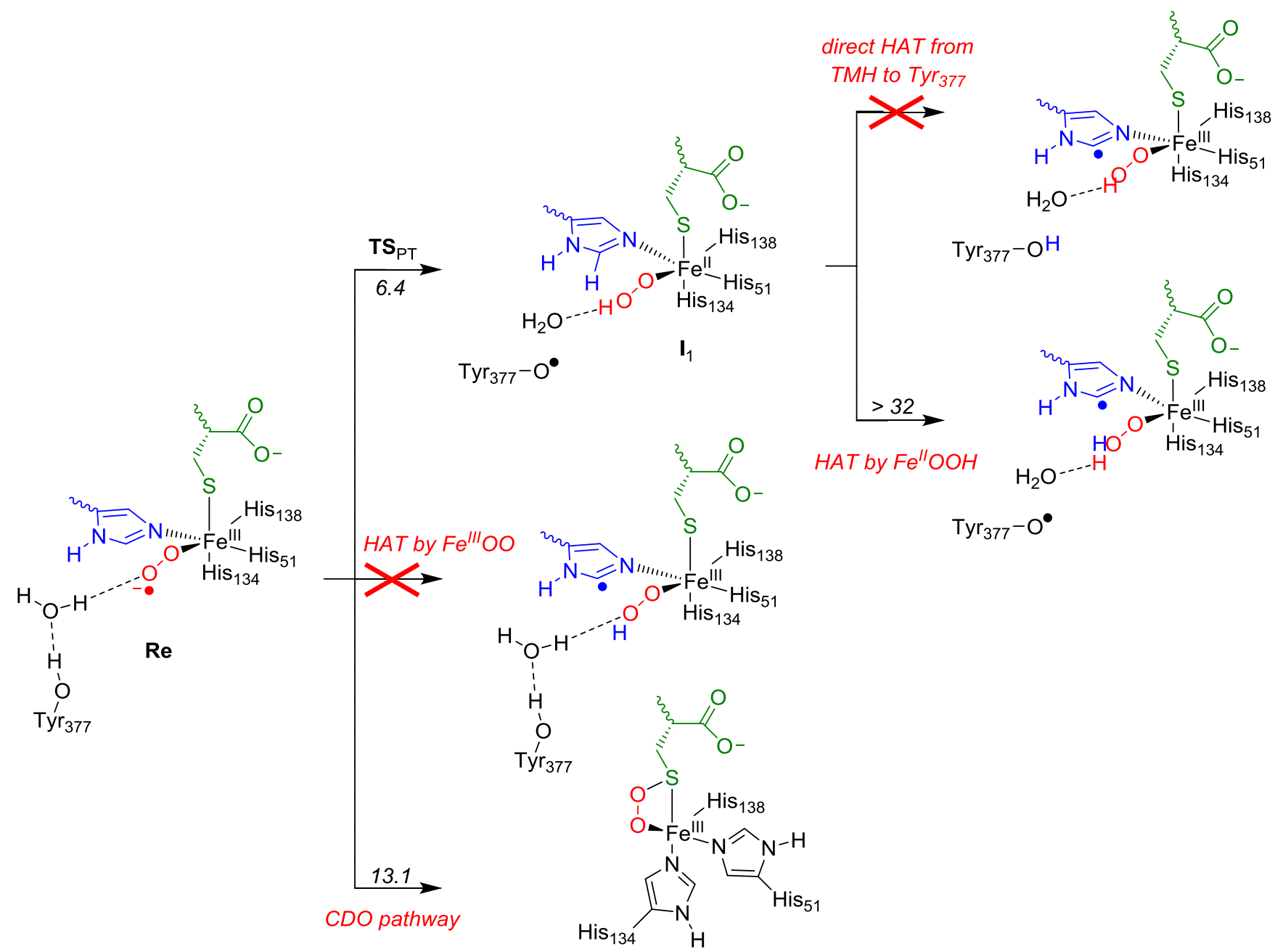

Figure 7. Alternative reaction pathways for the sulfoxide synthase mechanism of EgtB. Explanations see text. Barriers are given in $\mathrm{kcal} \mathrm{mol}^{-1}$ relative to ${ }^{5} \mathbf{R e}$.

Alternative mechanisms and by-product channels. Although the low-energy process described in Figures 3 and 4 appears to give accessible energies for the protein at room temperature, we investigated also a series of alter- 
native pathways to rule out the formation of side reactions and by-products, Figure 7. As some nonheme iron(III)-superoxo complexes of dioxygenases and synthetic model complexes are known to react through hydrogen atom abstraction with substrates, ${ }^{41}$ we decided to investigate the hydrogen atom abstraction of the $\mathrm{CE} 1-\mathrm{H}$ bond by the reactant complexes ${ }^{3,5} \mathbf{R e}$ in snapshot $\mathrm{Sn}_{950}$ (middle reaction from $\mathbf{R e}$ in Figure 7 ). We find a high energy pathway that does not plateau into a local minimum, however. Therefore, a hydrogen atom abstraction by iron(III)-superoxo from the imidazole ring is difficult and possibly only achievable when the hybridization of $\mathrm{CE} 1$ changes from $\mathrm{sp}^{2}$ to $\mathrm{sp}^{3}$, e.g., through covalent binding of the sulfide. Hence, a reaction mechanism starting with hydrogen atom abstraction from CE1 will not be a likely pathway and has to follow the $\mathrm{C}-\mathrm{S}$ bond formation step. Therefore, we also calculated the C-S bond formation step starting from the iron(III)-superoxo complex ( $\left.{ }^{5} \mathbf{R e}\right)$, but here as well a high energy pathway was found. Therefore, from the iron(III)-superoxo reactant complex a proton transfer from TMH and a C-S bond formation step can both be ruled out. Consequently, the iron(III)superoxo will only react through either oxygen atom transfer (OAT) to thiolate or pick up a proton from a proton source such as $\mathrm{Tyr}_{377}$.

Of all pathways starting from the reactant complexes, the lowest energy reaction channel is the proton-coupledelectron-transfer from $\mathrm{Tyr}_{377}$ to the iron(III)-superoxo group to form iron(III)-hydroperoxo for which we located a barrier of only $6.4 \mathrm{kcal} \mathrm{mol}^{-1}$ (see Figure 3 above). Most probably, the energy of the reverse reaction is just high enough to prevent full equilibration between the reactant and $\mathbf{I}_{1}$ structures and the reaction will continue from $\mathbf{I}_{1}$. The obtained iron(III)-hydroperoxo species, however, is unable to react with the thiolate group of $\gamma \mathrm{GC}$ via a dioxygenation reaction as the calculated pathway gives a high energy process. Therefore, the protonation of the superoxo group is an essential initial step in the reaction mechanism to prevent the thiol dioxygenation reaction.

Subsequently, we considered a variety of possible reaction pathways starting from structure $\mathbf{I}_{1}$. As shown above in Figure 3 a C-S bond formation step of $12.7 \mathrm{kcal} \mathrm{mol}^{-1}$ above reactants leads to intermediate $\mathbf{I}_{2}$. The alternative mechanisms tested included a hydrogen atom abstraction from $\mathrm{TMH}$ by either the iron(II)-hydroperoxo group or directly to $\mathrm{Tyr}_{377}$. The direct proton transfer from the CE1$\mathrm{H}$ group of $\mathrm{TMH}$ via a chain of water molecules to $\mathrm{Tyr}_{377}$ was attempted through a geometry scan by relaying the hydrogen atom to a bridging water molecule. However, this scan did not lead to a maximum in energy and no stable product structure was found, but instead the energy continuously increased. Consequently, direct hydrogen atom transfer from $\mathrm{TMH}$ to $\mathrm{Tyr}_{377}$ is difficult and the bridging water molecules are unable to relay hydrogen atoms directly and no direct connection between Tyr and $\mathrm{TMH}$ exists. Clearly, water molecules are able to relay protons through a Grotthuss-type mechanism but not hydrogen atoms.

In addition, we investigated a hydrogen atom abstraction from the $\mathrm{CE} 1-\mathrm{H}$ group of $\mathrm{TMH}$ by the iron(II)hydroperoxo moiety to form iron(IV)-oxo and a water molecule. Although the iron(III)-hydroperoxo group is located in proximity of the $\mathrm{CE} 1-\mathrm{H}$ group, it appears energetically unfeasible to abstract a hydrogen atom. In particular, the geometry scans had high maxima with values of about 32 and $47 \mathrm{kcal} \mathrm{mol}^{-1}$ on the quintet and triplet spin state with respect to either ${ }^{5} \mathbf{I}_{1}$ or ${ }^{3} \mathbf{I}_{1}$. Consequently, the iron(III)-hydroperoxo species cannot act as an oxidant in the reaction mechanism and should react via hydrogen atom abstraction from substrate. Thus, the mechanism presented in Figure 3 is the lowest energy pathway for sulfoxide synthase by EgtB. Alternative reaction steps were tested and all were ruled out. Furthermore, many different plausible mechanisms have been reported and proposed in the literature. ${ }^{13,14,18,19,42}$ However, none of the mechanisms agrees on the sequence of the individual bond making and breaking events in the reaction cycle of EgtB. The major disagreement lies in the question as to whether sulfoxidation of $\gamma \mathrm{GC}$ preceeds $\mathrm{C}-\mathrm{S}$ bond formation $^{18,42 a}$ or vice versa. ${ }^{14}$ Our QM/MM studies support the latter in a novel mechanism that prevents dioxygenation of the cysteinate substrate. A key result we have obtained relates to a low-energy pathway that relies on $\mathrm{Tyr}_{377}$ as a transient electron- and proton-donor to the iron(III)-superoxide species. This proposal provides an intuitive mechanism by which $\mathrm{Tyr}_{377}$ can prevent $\gamma \mathrm{GC}$ dioxygenation, but also implicates that $\mathrm{Tyr}_{377}$ is not directly involved with $\mathrm{C}-\mathrm{H}$ bond cleavage. The latter agrees well with the experimental observation that mutation of $\mathrm{Tyr}_{377}$ to phenylalanine does not make $\mathrm{C}-\mathrm{H}$ bond cleavage rate limiting. ${ }^{43}$

Recent calculations by Siegbahn et al. ${ }^{18 \mathrm{~b}}$ examined the sulfoxidation-first route and produced a plausible mechanism. However, they predict a steady-state solvent kinetic isotope effect (KIE) that was not observed experimentally. ${ }^{43}$ Moreover, the sulfoxide product stereochemistry does not fit the empirical structure of the derived product. ${ }^{13 \mathrm{~b}}$ Furthermore, their model suggests that the pathways towards sulfoxide and dioxide products bifurcate after irreversible sulfoxidation of $\gamma \mathrm{GC}$. According to the corresponding energy landscape all intermediates after sulfoxidation and before $\mathrm{C}-\mathrm{H}$ bond cleavage are in equilibrium. Therefore, one would expect that deuterated TMH should reduce the sulfoxide to $\gamma \mathrm{GC}$ dioxide ratio. At least for the Tyr377Phe mutant of EgtB this substrate KIE on product distribution was not observed. ${ }^{43}$

\section{Conclusions.}

In conclusion, we have performed a high-level QM/MM study on the mechanism of sulfoxide synthase by EgtB enzymes, which is an enzyme involved in the biosynthesis of ergothioneine, an important natural amino acid in- 
volved in aging and anti-oxidant behavior in cells. ${ }^{44}$ These enzymes utilize molecular oxygen on a nonheme iron center that show structural and functional analogy to cysteine dioxygenase, but the reaction catalyzed by EgtB is remarkably complicated. In particular, it requires $\mathrm{C}-\mathrm{H}$ and $\mathrm{O}-\mathrm{O}$ bond cleavage and simultaneous $\mathrm{C}-\mathrm{S}$ and $\mathrm{S}-\mathrm{O}$ bond formation. We show, for the first time, that an active site tyrosine residue triggers protonation of the iron(III)-superoxo structure via a proton-coupledelectron-transfer. This is a low-energy pathway that prevents the iron(III)-superoxo group to react with sulfide and form cysteine sulfinic acid side-products. Instead, a subsequent $\mathrm{C}-\mathrm{S}$ bond formation step is triggered by sulfoxidation followed by proton transfer from iron(III)hydroperoxo to tyrosine. Alternative mechanisms were tested and ruled out as viable reaction pathways.

The calculations presented in this work show the sulfoxide synthase reaction is a challenging process in chemistry as many competing mechanisms may occur. Thus, Nature has created a specific enzyme class for this reaction, whereby a low-energy cysteine dioxygenation reaction is prevented through a proton-coupled-electrontransfer to form an iron(III)-hydroperoxo species. That way, a pathway is generated for $\mathrm{C}-\mathrm{S}$ bond formation between the cysteinate and imidazole groups of the two substrates. As such, the sulfoxide synthase reaction requires the bond formation processes in a specific order to obtain the required products. This is an important lesson for the future development for catalysts involved in reaction mechanisms for sulfoxide synthase type pathways and could make it a valuable template for the design of tailor-made biocatalysts.

\section{ASSOCIATED CONTENT}

Supporting Information. Absolute and relative energies, group spin densities and charges as well as details of geometry scans and Cartesian coordinates are available as Supporting Information. This material is available free of charge via the Internet at http://pubs.acs.org.

\section{AUTHOR INFORMATION}

\section{Corresponding Author \\ * sam.devisser@manchester.ac.uk (SPdV);} florian.seebeck@unibas.ch (FPS)

\section{Author Contributions}

The manuscript was written through contributions of all authors.

\section{ACKNOWLEDGMENT}

ASF thanks the Tertiary Education Trust Fund in Nigeria for a studentship. The EU-COST Network Explicit Control Over Spin-states in Technology and Biochemistry (ECOSTBio, CM1305) is acknowledged for support. FPS thanks the European Research Council for a Starting Grant.

\section{ABBREVIATIONS}

$\mathrm{CDO}$, cysteine dioxygenase; TMH, $\mathrm{N}$ - $\alpha$-trimethyl histidine; EgtB, ergothioneine biosynthesis; Asp, aspartate; Glu, glutamate; $\alpha \mathrm{KG}, \alpha$-ketoglutarate; $\gamma \mathrm{GC}, \gamma$-glutamyl cysteine; His, histidine; EPR, electron paramagnetic resonance; DFT, density functional theory; QM/MM, quantum mechanics/molecular mechanics; OAT, oxygen atom transfer; PT, proton transfer.

\section{REFERENCES}

(1) (a) Trewick, S. C.; Henshaw, T. F.; Hausinger, R. P.; Lindahl, T.; Sedgwick, B. Nature 2002, 419, 174-178. (b) Falnes, P. Ø.; Johansen, R. F.; Seeberg, E. Nature 2002, 419, 178-182. (c) O'Brien, P. J. Chem. Rev. 2006, 106, 720-752. (d) Yi, C.; Yang, C. G.; He, C. Acc. Chem. Res. 2oog, 42, 519-529. (e) de Visser, S. P.; Kumar, D. (Eds.), Ironcontaining enzymes: Versatile catalysts of hydroxylation reactions in nature. Royal Society of Chemistry, Cambridge, 2011.

(2) (a) Bruick, R. K.; McKnight, S. L. Science 2oo1, 294, 13371340. (b) Seifert, A.; Katschinski, D. M.; Tonack, S.; Fischer, B.; Santos, A. N. Chem. Res. Toxicol. 2oo8, 21, 341-348.

(3) (a) Stipanuk, M. H. Annu. Rev. Nutr. 2004, 24, 539-577. (b) Straganz, G. D.; Nidetzky, B. ChemBioChem. 20o6, 7, 1536-1548. (c) Joseph, C. A.: Maroney, M. J. Chem. Commun. 2007, 3338-3349. (d) de Visser, S. P. Coord. Chem. Rev. 2009, 253, 754-768.

(4) Heafield, M. T.; Fearn, S.; Steventon, G. B.; Waring, R. H.; Williams, A. C.; Sturman, S. G. Neurosci. Lett. 1990, 110, 216-220.

(5) (a) Solomon, E. I.; Brunold, T. C.; Davis, M. I.; Kemsley, J. N.; Lee, S.-K.; Lehnert, N.; Neese, F.; Skulan, A. J.; Yang, Y.-S.; Zhou, J. Chem. Rev. 200o, 100, 235-349. (b) Bugg, T. D. H. Curr. Opin. Chem. Biol. 2oo1, 5, 550-555. (c) Ryle, M. J.; Hausinger, R. P. Curr. Opin. Chem. Biol. 2oo2, 6, 193-201. (d) Costas, M.; Mehn, M. P.; Jensen, M. P.; Que Jr, L. Chem. Rev. 2004, 104, 939-986. (e) Abu-Omar, M. M.; Loaiza, A.; Hontzeas, N. Chem. Rev. 2005, 105, 22272252. (f) Krebs, C.; Fujimori, D. G.; Walsh, C. T.; Bollinger Jr, J. M. Acc. Chem. Res. 2007, 40, 484-492. (g) Bruijnincx, P. C. A.; van Koten, G.; Klein Gebbink, R. J. M. Chem. Soc. Rev. 20o8, 37, 2716-2744.

(6) (a) Que Jr, L. Nat. Struct. Biol. 20oo, 7, 182-184. (b) Kovaleva, E. G.; Lipscomb, J. D. Nat. Chem. Biol. 2oo8, 4, 186-193.

(7) (a) Chowdhury, R.; Hardy, A.; Schofield, C. J. Chem. Soc. Rev. 20o8, 37, 1308-1319. (b) Simmons, J. M.; Müller, T. A.; Hausinger, R. P. Dalton Trans. 2oo8, 5132-5142. (c) Hirao, H.; Morokuma, K. J. Am. Chem. Soc. 2011, 133, 1455014553.

(8) Pratter, S. M.; Konstantinovics, C.; DiGiuro, C. L. M.; Leitner, E.; Kumar, D.; de Visser, S. P.; Grogan, G.; Straganz, G. D. Angew. Chem. Int. Ed. 2013, 52, 9677-9681.

(9) (a) Dominy Jr, J. E.; Simmons, C. R.; Hirschberger, L. L.; Hwang, J.; Coloso, R. M.; Stipanuk, M. H. J. Biol. Chem. 2007, 282, 25189-25198. (b) Tchesnokov, E. P.; Fellner, M.; Siakkou, E.; Kleffmann, T.; Martin, L. W.; Aloi, S.; Lamont, I. L.; Wilbanks, S. M.; Jameson, G. N. L. J. Biol. Chem. 2015, 290, 24424-24437.

(10) Melville, D. B.; Horner, W. H.; Otken, C. C.; Ludwig, M. L. J. Biol. Chem. 1955, 213, 61-68. (b) Melville, D. B; Genghof, D. S.; Inamine, E.; Kovalenko, V. J. Biol. Chem. 1956, 223, 9-17. (c) Cheah, I. K.; Halliwell, B. Biochim. Bi- 
ophys. Acta 2012, 1822, 784-793. (d) Seebeck, F. P. J. Am. Chem. Soc. 2010, 132, 6632-6633.

(11) (a) Landgraf, B. J.; Booker, S. J. J. Am. Chem. Soc. 2016, 138, 2889-2892. (b) Rohac, R.; Amara, P.; Benjdia, A.; Martin, L.; Ruffié, P.; Favier, A.; Bertreau, O.; Mouesca, J.M.; Fontecilla-Camps, J. C.; Nicolet, Y. Nature Chem. 2016, 8, 491-500.

(12) (a) Paul, B. D.; Snyder, S. H. Cell Death Differ. 2009, 47, S149-S149. (b) Pluskal, T.; Ueno, M.; Yanagida, M. PLoS One 2014, 9, e97774. (c) Cheah, I. K.; Ong, R. L.; Gruber, J.; Yew, T. S.; Ng, L. F.; Chen, C. B.; Halliwell, B. Free Radical Res. 2014, 47, 1036-1045. (d) Bello, M. H.; BarreraPerez, V.; Morin, D.; Epstein, L. Fungal Genet. Biol. 2012, 49, 160-172. (e) Emani, S. C.; Williams, M. J.; Wiid, I. J.; Hiten, N. F.; Viljoen, A. J.; Pietersen, R. D.; van Helden, P. D.; Baker, B. Antimicrob. Agents Chemother. 2013, 57, 3202-3207.

(13) (a) Song, H.; Hu, W.; Naowarojna, N.; Her, A. S; Wang, S.; Desai, R.; Qin, L.; Chen, X.; Liu, P. Sci. Rep. 2015, 5 , 11870. (b) Vit, A.; Mashabela, G. T.; Blankenfeldt, W.; Seebeck, F. P. ChemBioChem 2015, 16, 1490-1496.

(14) Goncharenko, K. V.; Vit, A.; Blankenfeldt, W.; Seebeck, F. P. Angew. Chem. Int. Ed. 2015, 54, 2821-2824.

(15) Driggers, C. M.; Cooley, R. B.; Sankaran, B.; Hirschberger, L. L.; Stipanuk, M. H.; Karplus, P. A. J. Mol. Biol. 2o13, $425,3121-3136$.

(16) (a) Siakkou, E.; Rutledge, M. T.; Wilbanks, S. M.; Jameson, G. N. L. Biochim. Biophys. Acta 2011, 1814, 20032009. (b) Li, W.; Blaesi, E. J.; Pecore, M. D.; Crowell, J. K.; Pierce, B. S. Biochemistry 2013, 52, 9104-9119. (c) Davies, C. G.; Fellner, M.; Tchesnokov, E. P.; Wilbanks, S. M.; Jameson, G. N. L. Biochemistry 2014, 53, 7961-7968. (d) Fellner, M.; Aloi, S.; Tchesnokov, E. P.; Wilbanks, S. M.; Jameson, G. N. L. Biochemistry 2016, 55, 1362-1371.

(17) (a) Aluri, S.; de Visser, S. P. J. Am. Chem. Soc. 2007, 129, 14846-14847. (b) Kumar, D.; Thiel, W.; de Visser, S. P. J. Am. Chem. Soc. 2011, 133, 3869-3882. (c) de Visser, S. P.; Straganz, G. D. J. Phys. Chem. A 2009, 113, 1835-1846.

(18) (a) Bushell, E. A. C.; Fortowsky, G. B.; Gauld, J. W. Inorg. Chem. 2012, 51, 13351-13356. (b) Wei, W.-J.; Siegbahn, P. E. M.; Liao, R.-Z. Inorg. Chem. 2017, 56, 3589-3599.

(19) Goncharenko, K. V.; Seebeck, F. P. Chem. Commun. 2016, 52, 1945-1948.

(20) (a) Quesne, M. G.; Latifi, R.; Gonzalez-Ovalle, L. E.; Kumar, D.; de Visser, S. P. Chem. Eur. J. 2014, 20, 435-446. (b) Quesne, M. G.; Borowski, T.; de Visser, S. P. Chem. Eur. J. 2016, 22, 2562-2581.

(21) (a) Porro, C. S.; Sutcliffe, M. J.; de Visser, S. P. J. Phys. Chem. A 2009, 113, 11635-11642. (b) Hernández-Ortega, A.; Quesne, M. G.; Bui, S.; Heuts, D. P. H. M.; Steiner, R. A.; Heyes, D. J.; de Visser, S. P.; Scrutton, N. S. J. Biol. Chem. 2014, 289, 8620-8632. (c) Ji, L.; Faponle, A. S.; Quesne, M. G.; Sainna, M. A.; Zhang, J.; Franke, A.; Kumar, D.; van Eldik, R.; Liu, W.; de Visser, S. P. Chem. Eur. J. 2015, 21, 9083-9092. (d) Hernández-Ortega, A.; Quesne, M. G.; Bui, S.; Heyes, D. J.; Steiner, R. A.; Scrutton, N. S.; de Visser, S. P. J. Am. Chem. Soc. 2015, 137, 7474-7487. (e) Faponle, A. S.; Quesne, M. G.; de Visser, S. P. Chem. Eur. J. 2016, 22, 5478-5483.

(22) Dolinsky, T. J.; Czodrowski, P.; Li, H.; Nielsen, J. E.; Jensen, J. H.; Klebe, G.; Baker, N. A. Nucleic Acids Res. 2007, 35, W522-W525.

(23) Brooks, B. R.; Bruccoleri, R. E.; Olafson, B. D.; Swaminathan, S.; Karplus, M. J. Comput. Chem. 1983, 4, 187-217.
(24) (a) Bakowies, D.; Thiel, W. J. Phys. Chem. 1996, 10o, 10580-10594. (b) Hratchian, H. P.; Parandekar, P. V.; Raghavachari, K.; Frisch, M. J.; Vreven, T. J. Chem. Phys. 2008, 128, 034107. (c) Hitzenberger, M.; Hofer, T. S. J. Comput. Chem. 2015, 36, 1929-1939.

(25) Ahlrichs, R.; Bär, M.; Häser, M.; Horn, H.; Kölmel, C. Chem. Phys. Lett. 1989, 162, 165-169.

(26) Todorov, I. T.; Smith, W.; Trachenko, K.; Dove, M. T. J. Mater. Chem. 2006, 16, 1911-1918.

(27) Smith, W.; Forester, T. R. J. Mol. Graphics 1996, 14, 136141.

(28) Sherwood, P. J. Mol. Struct. 2003, 632, 1-28.

(29) (a) Becke, A. D. J. Chem. Phys. 1993, 98, 5648-5652. (b) Lee, C.; Yang, W.; Parr, R. G. Phys. Rev. B 1988, 37, 785789 .

(30) Schafer, A.; Horn, H.; Ahlrichs, R. J. Chem. Phys. 1992, 97, 2571-2575.

(31) (a) Wachters, A. J. H. J. Chem. Phys. 1970, 52, 1033-1036. (b) Hay, P. J. J. Chem. Phys. 1977, 66, 4377-4384. (c) Bauschlicher Jr., C. W.; Langhoff, S. R.; Partridge, H.; Barnes, L. A. J. Chem. Phys. 1989, 91, 2399-2411. (d) Krishnan, R.; Binkley, J. S.; Seeger, R.; Pople, J. A. J. Chem. Phys. 1980, 72, 650-654.

(32) (a) Becke, A. D. Phys. Rev. A 1988, 38, 3098-3100. (b) Perdew, J. P. Phys. Rev. B 1986, 33, 8822-8824.

(33) Adamo, C.; Barone, V. J. Chem. Phys. 1999, 110, 6158-6169.

(34) Cantú Reinhard, F. G.; Faponle, A. S.; de Visser, S. P. J. Phys. Chem. A 2016, 120, 9805-9814.

(35) Tchesnokov, E. P.; Faponle, A. S.; Davies, C. G.; Quesne, M. G.; Turner, R.; Fellner, M.; Souness, R. J.; Wilbanks, S. M.; de Visser, S. P.; Jameson, G. N. L. Chem. Commun. 2016, 52, 8814-8817.

(36) (a) Borowski, T.; Bassan, A.; Siegbahn, P. E. M. Chem. Eur. J. 2004, 10, 1031-1041. (b) Nemukhin, A. V.; Topol, I. A.; Cachau, R. E.; Burt, S. K. Theor. Chem. Acc. 2oo6, 115, 348-353. (c) Cicero, G.; Carbonera, C.; Valegård, K.; Hajdu, J.; Andersson, I.; Ranghino, G. Int. J. Quant. Chem. 2007, 107, 1514-1522. (d) Sinnecker, S.; Svensen, N.; Barr, E. W.; Ye, S.; Bollinger Jr, J. M.; Neese, F.; Krebs, C. J. Am. Chem. Soc. 2007, 129, 6168-6179. (e) Chen, H.; Lai, W.; Yao, J.; Shaik, S. J. Chem. Theory Comput. 2011, 7, 30493053. (f) Du, L.; Gao, J.; Liu, Y.; Liu, C. J. Phys. Chem. B 2012, 116, 11837-11844. (g) Dong, G.; Shaik, S.; Lai, W. Chem. Sci. 2013, 4, 3624-3635. (h) Dong, G.; Lu, J.; Lai, W. ACS Catal. 2016, 6, 3796-3803. (i) Wójcik, A.; Radoń, M.; Borowski, T. J. Phys. Chem. A 2016, 120, 1261-1274. (j) Mai, B. K.; Kim, Y. Inorg. Chem. 2016, 55, 3844-3852.

(37) (a) Bassan, A.; Borowski, T.; Siegbahn, P. E. M. Dalton Trans. 2004, 3153-3162. (b) Wójcik, A.; Broclawik, E.; Siegbahn, P. E. M.; Lundberg, M.; Moran, G.; Borowski, T. J. Am. Chem. Soc. 2014, 136, 14472-14485. (c) Fang, D.; Cisneros, G. A. J. Chem. Theory Comput. 2014, 10, 51365148.

(38) (a) de Visser, S. P. Angew. Chem. Int. Ed. 2006, 45, 17901793. (b) de Visser, S. P. J. Am. Chem. Soc. 2oo6, 128 , 9813-9824. (c) de Visser, S. P. Chem. Commun. 2007, 171173. (d) Godfrey, E.; Porro, C. S.; de Visser, S. P. J. Phys. Chem. A 2008, 112, 2464-2468. (e) Karamzadeh, B.; Kumar, D.; Sastry, G. N.; de Visser, S. P. J. Phys. Chem. A 2010, 114, 13234-13243.

(39) (a) Tchesnokov, E. P.; Fellner, M.; Siakkou, E.; Kleffmann, T.; Martin, L. W.; Aloi, S.; Lamont, I. L.; Wilbanks, S. M.; Jameson, G. N. L. J. Biol. Chem. 2015, 290, 24424-24437. (b) Fellner, M.; Siakkou, E.; Faponle, A. S.; Tchesnokov, 
E. P.; de Visser, S. P.; Wilbanks, S. M.; Jameson, G. N. L. J. Biol. Inorg. Chem. 2016, 21, 501-510.

(40) (a) de Visser, S. P.; Tan, L. S. J. Am. Chem. Soc. 2oo8, 130, 12961-12974. (b) Sallmann, M.; Kumar, S.; Chernev, P.; Nehrkorn, J.; Schnegg, A.; Kumar, D.; Dau, H.; Limberg, C.; de Visser, S. P. Chem. Eur. J. 2015, 21, 7470-7479.

(41) (a) Lundberg, M.; Siegbahn, P. E. M.; Morokuma, K. Biochemistry 2008, 47, 1031-1042. (b) Latifi, R.; Tahsini, L.; Nam, W.; de Visser, S. P. Phys. Chem. Chem. Phys. 2012, $14,2518-2524$.
(42) (a) Braunshausen, A.; Seebeck, F. P. J. Am. Chem. Soc. 2011, 133, 1757-1759. (b) Mashabela, G. T. M.; Seebeck, F. P. Chem. Commun. 2013, 49, 7714-7716. (c) Song, H.; Leninger, M.; Lee, N.; Liu, P. Org. Lett. 2013, 15, 4854-4857.

(43) Goncharenko, K. V.; Seebeck, F. P. Chem. Commun. 2016, 52, 1945-1948.

(44) (a) Halliwell, B.; Cheah, I. K.; Drum, C. L. Biochem. Biophys. Res. Commun. 2016, 470, 245-250. (b) Cheah, I. K.; Halliwell, B. Biochim. Biophys. Acta 2012, 1822, 784-793.

Graphic entry for the Table of Contents (TOC):
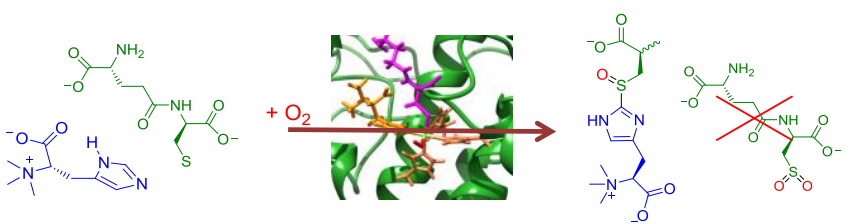